\title{
CULTURA: IMPLICAÇÕES POLÍTICO-PEDAGÓGICAS NAS PRÁTICAS EDUCATIVAS (?)
}

\author{
Márcio Penna Corte Real
}

\section{INTRODUÇÃO}

A idéia de escrever este artigo está intimamente ligada aos caminhos que venho percorrendo ultimamente na minha formação escolar de profissional da educação. Coloco-me, portanto, sob o ponto de vista de quem tem vivido numa comunidade de investigadores ativos - PPGE/CE/UFSM - e de quem tem interagido educacionalmente com movimentos sociais - movimentos de cultura negra e dos trabalhadores rurais sem terra. Meu ponto de vista, para que fique claro, é de quem vê nos movimentos sociais tanto um problema político, quanto educativo. Isto inclui minhas opções teórico-práticas.

Para realizar a discussão que me proponho e que entendo ser inicial, sobre a cultura e suas implicações político-pedagógicas nas práticas educativas, tocarei em pontos que, na minha leitura, se somam.

Num primeiro momento, faço um panorama da educação dialógicoproblematizadora freireana. E nele, explicito a idéia de síntese cultural, como forma de um balizamento para a elaboração de programas educativos problematizadores.

Logo após, proponho uma breve análise dos estudos culturais a partir do multiculturalismo e da educação Intercultural. E coloco um contraponto a partir da educação dialógico-problematizadora. Um outro ponto é o que diz respeito à didática e organização do trabalho educativo a partir de concepções educacionais sócio-críticas.

$\mathrm{Na}$ ultima parte do texto, trato sobre a noção de que o ato de educar é essencialmente uma ação político-pedagógica. Essa questão chama atenção, neste momento, em especial, pois tem me assustado a neutralidade com que muitos de nós, educadores, temos visto a nossa tarefa social de educar. Tenho ouvido afirmações como "essas questões de cunho ideológico não são bem vistas pela minha abordagem metodológica". Ora, será que educar é uma prática social que deva ser engessada por uma abordagem metodológica? Ou implica uma opção de mundo e de seres humanos que tenhamos? É o que tento discutir neste item.

O termo cultura, para ser dito, é entendido, de um lado, como aqueles elementos que caracterizam um povo ou grupo social no seu modo de vida, seu patrimônio material, seus artefatos, suas crenças, enfim, seus hábitos de vida. E, de outro lado, a cultura é a própria expressão dos conflitos sociais e da natureza humana de transformar seu mundo. Ou seja, a cultura é uma práxis erguida nos pilares da história. Por isso, um elemento para ser explorado nas práticas educativas. 


\section{UM PANORAMA DA EDUCAÇÃO DIÁLÓGICO-PROBLEMATIZADORA}

Com a produção intelectual do Paulo Freire nos anos 60 se inaugura o ciclo moderno da educação emancipadora (VARGAS, 2000:5). Este momento, intimamente relacionado com o movimento modernista brasileiro da década 30 , viria a influenciar de maneira importante o trabalho de Paulo Freire na sua relação com a cultura popular.

Neste sentido, o clima existente no Brasil da década de 30 contribuiu para que, posteriormente, o Freire dos anos 60 fosse influenciado pela relação com a cultura popular. E, ao exemplo de modernistas como Mário de Andrade, no envolvimento com movimentos de cultura popular, como no ISEB (Instituto Superior de Estudos Brasileiros), teria na cultura um projeto de emancipação popular, através do desenvolvimento de sua Pedagogia da Libertação (SCHELLING, 1990).

Num segundo momento, em torno dos anos 80 , salienta-se ainda a influência de Freire numa prática pedagógica que apontou para o desenvolvimento de mapas intelectuais e políticos abertos para a recriação constante (Ibid., p.6).

O que destaco deste momento é a relação com o desenvolvimento de trabalhos, mesmo mais atuais, que influenciam diretamente a didática e organização do trabalho escolar. Um exemplo claro seria a proposta metodológica dos três momentos pedagógicos-problematizadores - problematização inicial, organização e aplicação do conhecimento — de ANGOTTI e DELIZOIKOV (1990). Estes momentos pedagógicos visam a garantir a dialogicidade em cada etapa educativa (aula) e servem para investigar as visões dos educandos (a cultura) sobre um determinado tema abordado.

Avançando um pouco mais, percebo uma vertente para a investigação educacional que diria, parafraseando Vargas, dá conta do retorno à primeira utopia freireana expressa no diálogo cultural e na transformação surgida dos movimentos sociais e cidadãos (Ibid., p.6).

Aí percebo a relação com a idéia de síntese cultural desenvolvida por Freire em trabalhos como na sua Pedagogia do Oprimido (1987), que procurava incorporar o modo de vida do povo, ou seja a cultura, ao seu programa educacional problematizador, abordando, desta forma, tanto o aspecto epistemológico e organizacional, como uma educação caracterizada pelo ato pedagógico indissociável do político.

Além disso, saliento a abertura que este momento tem de fundamental no que tange os movimentos sociais organizados. Hoje, entendidos, ao meu ver, como um campo fundamental para a qualificação da investigação educacional. E, simultaneamente, um espaço privilegiado para a formação de professores conectados com a realidade desafiadora vigente no contexto das lutas sociais.

Neste sentido, este terceiro momento, no inicio dos anos 90, é caracterizado como 
uma fase em que a educação emancipadora é a possibilidade de construir uma pedagogia do conflito e de poderes transformadores a partir dos movimentos sociais e do diálogo cultural (Ibid., p.7).

Nesse sentido, o que-fazer pedagógico necessita de uma teoria que ilumine a prática através da ação e reflexão em situações sócio-educativas. Ou seja, reivindica-se a produção de um conhecimento educacional conecto com a prática educativa, com as suas exigências e seus desafios ante os tempos históricos/culturais formadores do tecido da disputa social.

\section{PERSPECTIVAS DOS ESTUdOS CULTURAIS}

Hoje em dia, a partir da idéia de que a crescente globalização econômica e o desenvolvimento das comunicações têm acarretado um maior contato entre os povos, demarcando o horizonte das lutas sociais, surgem propostas como a Educação Intercultural.

Estas propostas têm se demonstrado no Brasil, em especial, defendida em trabalhos como os de CANDAU (1998) e FLEURI (2000), dando uma significativa atenção sobre a elaboração de questões educacionais pertinentes, na relação com os movimentos sociais e com a cultura popular.

No entanto, há limites e possibilidades na proposta da educação Intercultural, inclusive em pontos relativos à didática e formação de professores. Destacam-se essencialmente dois aspectos: a configuração de estratégias de organização educativa; e o enfoque na epistemologia da investigação educacional.

Em MORGADO (2000), para se ter o exemplo, encontra-se a proposição de que a atuação em contextos educacionais como o dos pré-vestibulares populares podem constituir agentes significativos no empoderamento dos agentes sociais. Entendendo empoderamento, como parafraseio na referida autora, como sendo o controle ou o ganho de controle pessoal através de auto-estima e capacidade interna.

Em um primeiro momento, a discussão realizada no referido trabalho, acerca do referencial teórico da educação Intercultural, aponta para uma análise da polissemia em relação ao multiculturalismo.

Assim, o que é entendido como polissemia -- diferentes significados das palavras - relaciona a Educação Intercultural com a perspectiva do multiculturalismo crítico. Entendendo que o multiculturalismo critico "privilegia a transformação das relações sociais, culturais e institucionais nas quais os significados são gerados. Recusa-se a entender a cultura como não-conflitiva, harmoniosa ou consensual" (MCLAREN apud MORGADO, 2000:3).

Nessa ótica, o que diferenciaria o multiculturalismo, ainda que o crítico, da Educação Intercultural, seria que o primeiro faz referência às diferentes culturas existentes numa mesma sociedade; enquanto que a segunda opção colocaria uma forma de lidar com tal realidade (ibid.,2000:3). 
No entanto, há que se reforçar a idéia de superar a consciência do caráter multicultural. Isto se tomarmos como considerável a advertência de CANDAU, de que "portanto, a consciência do caráter multicultural de uma sociedade não leva espontânea e necessariamente ao desenvolvimento de uma dinâmica social informada pelo caráter Intercultural" (1998:184).

Na via oposta, da constatação ou consciência do caráter multicultural da sociedade, a educação Intercultural seria antes uma forma de educação, que: requer que se trate nas instituições educativas os grupos populares não como cidadãos de segunda categoria, mas que se reconheça seu papel ativo na elaboração, escolha e atuação das estratégias educativas" (FLEURI, 2000:4, grifos meus).

A partir da idéia colocada acima, nota-se que a Educação Intercultural sinaliza como elementos pontuais no que diz respeito ao fazer educativo, relacionados ao âmbito da didática. Em outras palavras, entendo que está se evidenciando, em verdade, uma forma de abordar aspectos de caráter metodológico e organizacional da prática educativa em contextos sociais diversos.

Meu argumento, no entanto, é que não podemos deixar escapar pontos centrais para a investigação educativa. Estes são encontrados, para se ter uma idéia, na desafiante colocação de FLEURI, já que

O quadro da complexidade das relações sociais no mundo contemporâneo requer novas orientações sociais epistemológicas no campo da pesquisa e da educação. Nesta direção, aparece como questão central na prática pedagógica a visão de mundo dos sujeitos em formação, assim a relação entre tais visões e os modelos (de conhecimento, de avaliação de comportamento) transmitidos através de situações educativas, particularmente na escola[...] traz conseqüências para a elaboração dos métodos e das técnicas de ação pedagógica e de transmissão da cultura oficial (2000:3, grifos meus).

Desta forma, o que se está colocando 'em jogo' é a postulação de uma educação que vá além da idéia de que a diversidade cultural possa evidenciar uma boa leitura dos diversos agentes presentes nas prática educativas. De outra forma, também não se está fomentando recursos para a constatação, quase que absolutamente óbvia, da diversidade cultural.

Em um caráter mais urgente, implica, sim, ao tomar como desafiadora a realidade social das práticas educativas, propor-Ihe, então, formas para que aquelas sejam guiadas desde dentro de sentidos metodológicos e epistemológicos.

Este critério seria um ponto fundamental para superar o acentuado grau de verificação da investigação educativa acompanhado, no entanto, de um baixo grau 
de proposição. Este, aliás, é um problema já apontado com propriedade, inclusive na relação da cultura dos movimentos sociais com o ato educativo, segundo a formulação de uma ação cultural para a liberdade de FREIRE

Considerando, porém, que o ato de desvelar a
realidade, indiscutivelmente importante, não
significa engajamento automático na ação
transformadora da mesma, o problema que
nos apresenta é de encontrar em cada realidade
histórica, os caminhos de ida e volta entre o
desvelamento da realidade e a prática dirigida no
sentido de sua transformação (1982: 60, grifos
meus).

Neste sentido, é possível interpretar-se que os caminhos de ida e volta, na verdade, são uma constante ação-reflexão na prática educativa num constante que-fazer. $O$ que necessariamente implica em redimensionar os sentidos metodológicos e epistemológicos da investigação educativa, ante a realidade sócio-cultural desafiadora.

\section{A DIDÁTICA NA RESOLUÇÃO DE PROBLEMAS SOCIOCULTURAIS}

A didática pode ser reivindicada como uma forma de abordar o ato educativo, tanto em termos metodológicos e epistemológicos, a partir de uma dinâmica educativa/investigativa. Pode implicar, ainda, numa esfera mais ampla no que tange a resolução de problemas educativos/sociais.

Deste modo, nos é 'dado', enquanto educadores(as), a responsabilidade de direcionar transformações na prática educativa no campo da investigação didática; se tomarmos a ordem colocada na contradição das sociedades tecidas pela disputa que impõe rever a racionalidade das nossas práticas sócio-educativas.

Neste sentido, seria necessário rever os espaços da investigação educacional de forma que a escola e as instituições de formação de professores pudessem incorporar, ainda mais, a realidade social. Isto pode acontecer na medida que a investigação didática e as questões de formação de professores, tomem como um problema, político-pedagógico, campos como os movimentos sociais e as práticas culturais que representam parte significativa das problemáticas sociais.

Assim, a partir de teorias sócio-críticas sintonizando a prática educacional escolar formal e, quiçá, colaborando ativamente no campo dos conteúdos educacionais com os movimentos sociais, por exemplo, poderia se estar firmando parcerias no sentido de orientar a ação educativa. O que, por sua vez, reforçaria a propriedade humanamente social do ato educativo.

Neste caminho, sou conivente com ANTOLIN (1996: 91) na proposição de que "A partir daí teorias críticas estão desenvolvendo uma plataforma para elaboração de uma teoria pedagógica para abordar e resolver problemas da prática". Dentre estas teorias, o autor sinaliza com a idéia de que um de seus melhores 
precedentes está na pedagogia de PAULO FREIRE (Ibid., 91).

Entendendo, pois, que aí encontra-se uma esfera em que a educação é concebida abordando o político-pedagógico a partir de um programa de investigação educacional sócio-crítico.

Este caráter se demonstra razoavelmente bem em trabalhos como na Pedagogia do Oprimido (FREIRE, 1987). No terceiro capitulo desta obra apresentam-se etapas organizativas do processo educativo; desde o levantamento preliminar dos temas geradores até ação propriamente dita; que seria a codificação/descodificação como forma de problematização da realidade sóciocultural do ato educativo.

Esta dinâmica investigativa da educação freireana é balizada pelo seu fundamento dialógico. O que coloca o diálogo como um forma de buscar os conteúdos programáticos para o ato educativo, então concebido numa constante revisão da prática educativa. Em outras palavras, busca-se conceber a prática educativa como campo privilegiado da investigação educacional sócio-crítica.

Desta forma, seria de reivindicar o potencial de incorporar a didática numa concepção de prática educativa/formação de professores, em que as questões metodológicas e epistemológicas não sejam dispares das que impulsionam a prática educativa. Ou seja, deveria primar-se, sobretudo, pela formação de professores que, de fato, sejam agentes potencializadores das transformações sócio-culturais que os tempos históricos vão nos colocando como problemas.

\section{EDUCAR: UM ATO POLÍTICO-PEDAGÓGICO (?)}

A forma de entender o ato educativo é, quase sempre, responsável pelo enfoque dado na ação e organização do trabalho escolar. Por exemplo, existem leituras de mundo revestidas de ideais de promover práticas educativas solidárias, que primam pela elevação da cultura humana e da justiça social. Estas, normalmente, têm claro o componente político de que está imbricado o espaço pedagógico.

Por outro lado, existe a possibilidade de fechar-se os olhos para os problemas sociais/educativos de nosso tempo. E, como se fosse possível, primar pelo trabalho de desenvolver os conteúdos escolares de forma apolítica. Conteúdos que, desta forma, não são problematizados nem tensionados. É, portanto, desconsiderado que os conteúdos vêm depositados em garrafas do saber (ANGOTTI, 1991). E não se discute o vínculo ou não que possam ter com o meio sócio-cultural e, o que é pior, o quanto de ideológico cada garrafa do saber carrega consigo. Já que, muitas vezes, o educador-educando e o educandoeducador perdem o poder de deliberar sobre pacotes que vêm fechados.

"Desse ponto de vista, que é reacionário, o espaço pedagógico, neutro, é aquele em que se treinam os alunos para práticas apolíticas, como se a maneira humana de estar no mundo fosse ou pudesse ser uma maneira neutra." (FREIRE,1996:110). Esta forma neutra, apolítica, despida de contornos ideológicos é a maneira mais explicita de promoção e defesa das injustiças 
sociais. Nesse discurso, é usado como justificativa que a escola deve priorizar o preparo dos educandos(as) para o vestibular e para mundo do trabalho. No entanto, não é discutido que muitas crianças e adolescentes não terão acesso às poucas vagas das nossas universidades públicas e gratuitas. E, que o trabalho, historicamente, tem servido para promover a injustiça e a exploração sociais.

Desta forma, antes de recusarmos a possibilidade de que a escola pública, em especial, da educação infantil ao ensino superior, colabore na formação de nossos cidadãos, é preciso termos claro que existimos cultural e historicamente. Isto implica opções de mundo e de seres humanos que, nas práticas educativas, vão além de uma abordagem metodológica, por exemplo.

Educar/educar-se, nesse sentido, inclui opções políticas e ideológicas que, mesmo que não sejam explicitas, são responsáveis e colaboram no "perfil" dos cidadãos que, muitas vezes, têm na escola pública uma possibilidade ímpar de elevação cultural.

É nessa compreensão que educar não é tão somente um ato político-pedagógico. Sim. "Quando vivemos a autenticidade exigida pela prática de ensinar-aprender participamos de uma experiência total, diretiva, política, ideológica, gnosiológica. pedagógica, estética e ética, em que a boniteza deve achar-se de mãos dadas com a decência e com a sensibilidade." (FREIRE, ibid.: 26, grifos meus).

\section{CONSIDERAÇÕES FINAIS}

Em cada parte deste artigo fui abordando pontos que considerei pertinentes em relação à questão levantada, a cultura e suas implicações político-pedagógicas. Em um primeiro momento, a idéia de fazer um breve panorama da educação dialógico-problematizadora, na sugestão freireana, remete a analisar o papel da cultura como indicativo da organização educativa.

A abordagem dos estudos culturais, a partir do multiculturalismo e da educação intercultural, deixa em aberto, sobretudo, a questão de que aqueles ainda estão carentes no desenvolvimento de estratégias educativas que permitam lidar com o problema cultural das nossas sociedades.

Esta questão, creio eu, aponta avanços nos balizamentos educativos em termos da didática, potencializando a investigação educativa, conforme abordei. E, a partir de concepções educacionais sócio-críticas, a didática aponta para a resolução de problemas sócio-educativos, que, ao meu ver, são sócio-culturais.

Nesse sentido, estas questões se somam ante a tarefa social que está envolvido o trabalho político-pedagógico do educador(a). É preciso agirmos em termos do redimensionamento da organização das nossas práticas educativas e da racionalidade que as envolve, pautando pelo acesso ao patrimônio cultural, principalmente através da escola pública, aos cidadãos dos nossos tempos. Portanto, por um lado, querer garantir o acesso da mais alta cultura humana para todos pode parecer um sonho. Mas, por outro lado, é um sonho-real-possível, na medida que é um dos caminhos de promoção da justiça social. 


\section{BIBLIOGRAFIA}

ANGOTTI, J.; DELIZOICOV, D. Metodologia do ensino de ciências. São Paulo: Cortez, 1990.

ANGOTTI, J. Fragmentos e totalidades no ensino de ciências. Tese de Doutorado, FEUSP, 1991: 110-114.

BORGADO,P. O Pré-vestibular para negros e carentes(PVNC) no contexto dos Pré-vestibulares comunitários e o empoderamento de identidades sócio-culturais. In X ENDIPE, Anais em Cd/rom, Rio de Janeiro: 2000.

CANDAU, V. Intercularidade e educação escolar. In IX ENDIPE, Anais vol. 1/1. Águas de Lindóia:1998.

FLEURI, R. Educação Intercultural: desafios e perspectivas da identidade e pluralidade étnica no Brasil. Florianópolis MOVER/UFSC: 2000 (no prelo).

FREIRE, P. Ação cultural para a liberdade e outros escritos. 6 ed. Rio de Janeiro: Paz e Terra, 1982.

. Pedagogia do Oprimido. 17 ed. São Paulo: Paz e Terra, 1987.

Pedagogia da Autonomia: saberes necessários à prática educativa. São Paulo: Paz e Terra, 1996.

SCHELLING, Vívian. A Presença do povo na cultura brasileira: ensaio sobre o pensamento de Mário de Andrade e Paulo Freire. Tradução Federico Caroti, Campinas, UNICAMP, 1990.

VARGAS, J. Memoria e modernidad crítica de la educacion Latinoamericana: una leitura post-freireana. Disponível em http://www. Ceaal.org/Memoriaysenti.html, retirado da rede, 2000. 